\title{
Interannual weather variability and the challenges for Great Britain's electricity market design
}

Article

Accepted Version

Creative Commons: Attribution-Noncommercial-No Derivative Works 4.0

Coker, P. J., Bloomfield, H. C., Drew, D. R. and Brayshaw, D. J. (2020) Interannual weather variability and the challenges for Great Britain's electricity market design. Renewable Energy, 150. pp. 509-522. ISSN 0960-1481 doi:

https://doi.org/10.1016/j.renene.2019.12.082 Available at https://centaur.reading.ac.uk/88163/

It is advisable to refer to the publisher's version if you intend to cite from the work. See Guidance on citing.

To link to this article DOI: http://dx.doi.org/10.1016/j.renene.2019.12.082

Publisher: Elsevier

All outputs in CentAUR are protected by Intellectual Property Rights law, including copyright law. Copyright and IPR is retained by the creators or other copyright holders. Terms and conditions for use of this material are defined in the End User Agreement.

www.reading.ac.uk/centaur 
Central Archive at the University of Reading

Reading's research outputs online 


\title{
1 Interannual weather variability and the challenges for Great Britain's 2 electricity market design
}

\author{
3 Phil J. Coker ${ }^{\text {a }}$, Hannah C. Bloomfield ${ }^{\text {b }}$, Daniel R. Drew b, David J. Brayshaw ${ }^{\text {b,c }}$ \\ $4 \quad{ }^{\text {a }}$ School of Built Environment, University of Reading, Reading, UK \\ $5 \quad{ }^{\mathrm{b}}$ Department of Meteorology, University of Reading, Reading, UK \\ $6{ }^{\mathrm{c}}$ National Centre for Atmospheric Science, Department of Meteorology, University of Reading, \\ 7 Reading, UK
}

8 Abstract

9 Global growth in variable renewable generation has brought significant attention to the challenge of 10 balancing electricity supply and demand. However, inter-annual variability of energy resources has only recently begun to feature in energy system assessments and receives limited recognition in policy discussion, let alone policy design. Meteorological reanalysis datasets that blend modern modelling techniques with historic weather records are seeing increased application in energy system studies. This practice offers insights for market and policy design implications as governments seek to manage the changing energy landscape, as seen with the UK's introduction of the Electricity Market Reform policy package. Here we apply a concise, Load Duration Curve based approach to consider the market and policy implications of increasing variability in the Great Britain (GB) energy system. Our findings emphasise the growing inter-annual variability in operating opportunity for residual midmerit and even baseload generation, alongside implications for capacity assurance approaches. The growth in wind generation is seen to bring an accompanying opportunity for increased solar generation, with its lower inter-annual variability and largely uncorrelated annual characteristic. The results underscore the need for an increased recognition of inter-annual variability when addressing market design and incentive mechanisms.

24 Keywords

25 Wind

26 Solar

27 Renewable variability

28 Reanalysis

29 Curtailment

30 Energy markets

$31 \quad$ Highlights

32 Meteorological reanalysis datasets benefit energy system studies

33 Load duration curve approach complements sophisticated system models

34 Inter-annual variability has implications for energy and capacity (power) based markets

35 Blended renewables solutions help mitigate inter-annual variability 


\section{Introduction}

39 Global growth in variable renewable energy (VRE, primarily from wind and solar resources) has 40 brought significant attention to the challenge of balancing electricity supply and demand. However, assessments and receives limited recognition in policy discussion, let alone policy design. This might be considered surprising given the long-standing temperature sensitivity of electricity demand in many regions [1-3] and subsequent year to year variations. Such variability has typically been consigned to a treatment of long-term averages and 'weather adjusted' demand, as previously noted by $[4,5]$.

As operational experience with renewable generation has increased, so longer time series of power output have become available for energy system studies. For example, the ENTSO-E transparency portal now has generation and load data available for some 35 European Countries at sub-daily resolution for 2014-2018 [6]. Despite this growing experience, meteorological methods are still essential to assess the full range of potential weather impacts. In turn, longer time series of generation output have supported increasing accuracy in synthesising energy generation from weather data.

Reanalysis based methods combine historical atmospheric records with state-of-the-art Numerical Weather Prediction (NWP) tools to provide multi-decadal data sets with continuous, gridded, spatial and temporal coverage. Following common use within the meteorological community, reanalysis derived data have seen increasing application for energy-meteorology studies, e.g. [7-16]. Authors have investigated the impact of inter-annual variability on power system aspects including demand $[4,5,16]$, wind power generation $[13,14,17]$ and solar power generation [11]. Both demand and wind power exhibit substantial inter-annual variability, due to their predominant dependence on temperature and wind speed respectively [14]. The inter-annual variability of solar generation is small by comparison, though variability in summer output is still substantial [11]. Reanalysis data is produced by combining a short-range forecast with available observations, within the data assimilation window (typically 6-12 hours, see [18] for further details and [19] for implications of quality and quantity of observations). 'Modern' reanalysis datasets cover a relatively recent period, of several decades, where satellite observations are available. The MERRA dataset used in this study is a commonly used example of this type, described further in section 2.2.

Growing interest in high renewable energy systems has been accompanied by increasing sophistication in the variability implications assessed in system level energy studies. Gross et al. have reviewed and revisited the diversity of approaches used to assess the cost impacts of variability $[20,21]$. Meanwhile, modellers have moved to combine the insights of operational power system models with those from long term investment models [22]. Recently, hybrid modelling approaches have been combined with reanalysis derived data sets, highlighting the sub-optimal implications of planning power systems based on the weather in any one given year [23,24]. Care is needed, though, as such system modelling approaches are highly sensitive to some very uncertain cost assumptions [25]. As illustration, the UK Climate Change Committee [26] note cost estimates of onshore wind falling from above 80 to below $50 \mathrm{f} / \mathrm{MWh}$ in some three years (compares latest 2020 cost estimates with previous 2030 estimates used to inform the UK's fifth carbon budget in 2015). Such financial uncertainties bring a risk that weather sensitivities can be obscured and weather implications only partly appreciated.

The low marginal cost and non-dispatchable nature of VRE can bring a threat to the economic viability of other generating plant competing for market opportunity. This contributes to uncertainty regarding the most effective market design to assure policy aims. Hirth et al emphasise the significance of the 'utilisation effect' on residual plant, noting this as one aspect of 'profile costs', a sub-set of the integration costs of VRE. Wind profile costs are estimated to be around $15-25 € / \mathrm{MWh}$ at 30-40\% market share [27]. This disruption can be amplified for other power plant with extended start-up and cool down periods (typified by nuclear plant, but also seen to some extent with coal generators and high efficiency CCGT) and exacerbated by the capital-intensive nature common to most low carbon generation options (especially nuclear and Carbon Capture \& Storage). As a result, 
debate continues whether energy only markets can ensure supply adequacy, or supplementary

90 capacity assurance mechanisms are needed [28].

In response to these challenges, alongside the imperatives for decarbonisation, energy security and energy affordability, many countries have re-evaluated energy market design and / or introduced incentive mechanisms. The UK has introduced a package of legislative measures, under the Electricity Market Reform project. Experience from the early years operation of these collective measures is under close international scrutiny, given the shared global nature of the challenges reflected [29]. Two measures are of particular significance here:

- Contracts for Difference (CFD) provide an energy price mechanism to support new low carbon generation. 15 year CFD contracts have been awarded to renewables schemes including wind and solar generation, while a 40 year contract has been agreed for the new-build Hinkley Point nuclear scheme. This process has been accompanied by an increased openness in cost assumptions [30], including indicative load factor figures for generating plant, notably $93 \%$ for CCGT and $90 \%$ for nuclear. These are stated as 'maximum potential' values while levelised costs will be higher when plant is required to operate at lower load factors.

- The Capacity Mechanism ${ }^{1}$ seeks to assure security of supply through a capacity (power) based contribution. Contracts are available to all technologies that are not receiving other government incentives, including demand side solutions. The level of capacity procured for any given year is decided by the government, following a recommendation from National Grid. To determine this level, a reliability standard traditionally known as 'Loss of Load Expectation' (LOLE) has been set as no more than three hours per year [31]. (For a description of LOLE derivation see [32].) In practice, this standard typically translates to periods where the System Operator must take exceptional actions rather than direct supply interruption.

Interannual variability of energy and peak load have implications for the practical and economic effectiveness of such market mechanisms. Within the CFD design, strike prices are agreed based on a single long-term average capacity factor. Variability in actual, annual wind levels has the potential to lead to over or underpayments as a result. Within Capacity Mechanism implementation, close attention has been paid to long-term variability in establishing a target capacity margin; however with this target margin set in advance there is no provision to adjust for actual weather influence each year. With annual variations in peak, temperature sensitive electricity demand and wind contribution at the moment of peak demand this can result in seemingly unnecessary generation being funded some years, while shortfall of generation could still be expected during others.

In this paper, we combine reanalysis derived, multi-decadal time series of historic UK weather data with a Load Duration Curve (LDC) technique to explore the system implications of weather sensitivity, especially the inter-annual variability in wind, solar and temperature influence. The LDC approach entails certain simplifications but brings the advantage of isolating weather-based effects from other economic and technical uncertainties. It also allows simultaneous assessment of energy and power concerns. The challenge of long-term energy availability is quite distinct from the challenge of peaks in instantaneous energy transfer rate (power). Further, the LDC approach allows ready exploration of multiple years and extreme weather influences. We argue that the merits of this framework justify parallel use to complement the application of more sophisticated energy system models.

\footnotetext{
${ }^{1}$ During preparation of this paper, a standstill was imposed on the UK Capacity Mechanism following a judgment concerning State Aid interpretation at the General Court of the Court of Justice of the European Union. Although payments are not being made, the mechanism is still in operation, anticipating a full restoration of the scheme as soon as possible. See https://www.gov.uk/government/collections/electricity-market-reformcapacity-market.
} 


\subsection{The Load Duration Curve technique}

LDCs are a long-established analytical technique used by energy practitioners to assess the preferred generating mix in a given power system, e.g. as used by [33], described by [34] and revisited in [35]. Often applied for a single year, an LDC shows the power level that is exceeded for each incremental duration of the year. Figure 1 gives an example with a synthesised demand curve. Descriptors of electricity generation roles vary. In this paper, we adopt the terms peaking, load following and baseload, which can be broadly inferred as corresponding to horizontal areas on the left, middle and right of the plot, respectively. Figure 1 has also adopted a common approach to VRE, by subtracting generation in each hour from the demand requirement. This assumes a preference for renewable energy, reflecting the low marginal cost and low carbon credentials of such plant, and results in demand net renewable curves that show the operating opportunity available for other generating plant. We follow previous authors in adopting the term residual generation to collectively describe plant other than VRE.

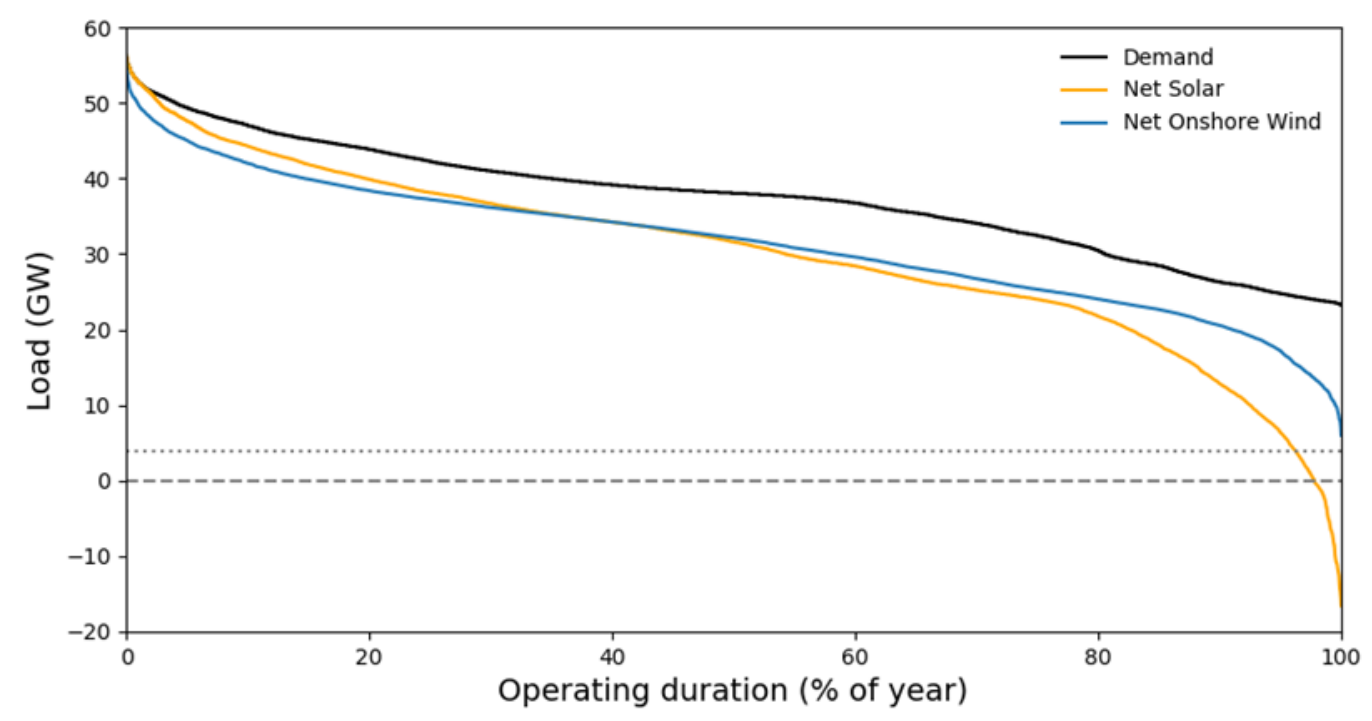

Figure 1. Example Load Duration Curve (LDC) - modelled energy timeseries for 2011. The dotted line indicates a reference level of non-variable baseload plant, reflecting anticipated nuclear new build (see 2.4 below).

\subsection{Data approaches and energy simulation}

This paper presents modelled electricity demand and supply for the Great Britain (GB) power system, derived from long term weather data sets. This allows combinations of weather from a known year with differing assumptions for the installed generating capacity cases. The reanalysis based models and subsequent LDC framework are readily adaptable to any country-scale power system, given the global nature of reanalysis data. In addition, information is required on installed renewable capacities and a minimum of one year of metered energy data to train the regression models (as is available from the ENTSOe transparency platform [6]).

The primary data source for the results presented below is the MERRA reanalysis [18]. MERRA data starts from the beginning of the modern satellite era, covering the period from January 1979 February 2016. An updated product, MERRA2 is now available [36]; however, all results below derive from MERRA following the extensive validation work completed to date for energy simulation.

Consistent hourly, GB-aggregated, reanalysis derived time series have been prepared for the period 1980 - 2015, covering simulated wind generation, solar generation and electricity demand. This follows work developed through a series of studies and extensively documented in previous papers. 
The data used in this study are freely available for download from the University of Reading Research 166 Data Archive [37].

167 For the wind power model, $2 \mathrm{~m}, 10 \mathrm{~m}$, and $50 \mathrm{~m}$ wind speeds on each horizontal level are bi-linearly interpolated to each wind farm's location. The wind speed is then vertically extrapolated to the turbine hub height, assuming a logarithmic change in wind speed with altitude. Hub-height winds are converted to wind farm normalised power output using a non-linear transform function and multiplied by the installed capacity to produce an estimate of farm output. Finally, the power output is summed over all the wind farms in Great Britain (GB) to produce an hourly time-series of GB-aggregated wind power generation. Extensive discussion of the model's validation is provided in [17]. Further development to better distinguish between onshore and offshore resource is covered in [9].

The solar power model assumes the GB distribution of solar panels as of June 2017 (when some 12.5 GW was installed). The model divides Great Britain into 9 regions, determining the spatiallyaveraged, hourly mean surface shortwave irradiance and $2 \mathrm{~m}$ air temperature for each region. Modelled data was compared with observations from Met Office weather stations and, consistent with the findings of Boilley and Wald [38], seen to overestimate irradiance. A quantile-quantile bias correction has therefore been applied to the regional irradiance data. No temperature correction was required. A multi-linear regression approach is used to determine solar PV generation from the meteorological variables. Model derivation is described in greater detail in [39].

Daily mean demand is determined using a multiple linear regression with daily average parameters trained against recorded demand data from 2006-2015. The daily mean $2 \mathrm{~m}$ temperature from MERRA is spatially averaged over Great Britain and used to create an effective temperature. Nonmeteorological demand drivers include the weekly cycle of demand, national holidays and long-term fluctuations due to changes in GDP, population growth and energy efficiency. The daily-mean demand data is downscaled to hourly resolution using a linear combination of four prescribed seasonal diurnal cycles. Full details of the model including the regression coefficients and its validation are given in [4].

\subsection{Capacity assumptions}

The analysis below assesses demand and supply combinations for two sets of assumed generation capacities. The capacity sets have been designed to ensure clarity of the role of VRE in the energy mix.

- Energy Equal-Capacities that would result in an equal annual, average energy contribution from each renewable resource. The blended case offers a total contribution from all resources with a combined output equal to the energy from the individual resources. To achieve this an extreme solar assumption is required, deemed unlikely until 2050 at the earliest. Meanwhile wind capacities for the blended case must be held slightly below current levels.

- 2030 Plausible - Here each case represents a plausible maximum, with individual resource capacities drawn from different National Grid scenarios and a blend drawn from the scenario with the highest overall renewable contribution. 2030 falls within the timeframe of influence of current energy policy.

Table 1 presents weighting factors used in this paper to establish the installed generation assumptions. Long-term average capacity factors ${ }^{2}$ are calculated from the wind and solar power models (described in section 2.2). The weighting factor is calculated as the long-term capacity factor for solar divided by the relevant long-term wind capacity factor. These weighting factors are then applied as a ratio in calculating the Energy Equal capacity assumptions presented in Table 2.

Table 2 presents the two sets of four capacity assumptions that are used throughout. Each set comprises one value for each of the three individual resources and a single blend of all three. Relevant

\footnotetext{
${ }^{2}$ Capacity factor is a common usage, though often substituted with load factor, to describe 'Energy that can be produced by a generator as a percentage of that which would be achieved if the generator were to operate at maximum output $100 \%$ of the time' [21]. This source also includes an extensive glossary of other energy system terminology.
} 
reference generation capacities have been selected from National Grid's 2018 Future Energy

Scenarios (FES) [40]. The FES scenarios, from the UK electricity system operator, reflect extensive stakeholder consultation adding credibility to their use in studies of this type. These scenarios include capacity projections for each year through to 2050, with particular attention given to 2030 and 2050. Values have been taken from the National Grid scenario which provides the most relevant figure for each of our capacity assumptions. The source scenario and year is stated where appropriate.

\section{Table 1 Long term capacity factors, from hourly reanalysis derived energy timeseries from 1980-2015}

\begin{tabular}{|l|c|c|}
\hline & $\begin{array}{c}\text { Capacity Factor } \\
\text { (36 year mean) }\end{array}$ & $\begin{array}{c}\text { Weighting } \\
\text { factor }\end{array}$ \\
\hline Onshore wind & 28.80 & 0.389 \\
\hline Offshore wind & 37.65 & 0.297 \\
\hline Solar & 11.20 & 1 \\
\hline
\end{tabular}

Table 2 Capacity case assumptions. Installed capacities $(G W)$, with National Grid scenario indicated in parenthesis where relevant.

222 (CR - Community Renewables, 2D - Two Degrees, SP - Steady Progression. 20, 30, 50 indicate projected years - 2020 etc)

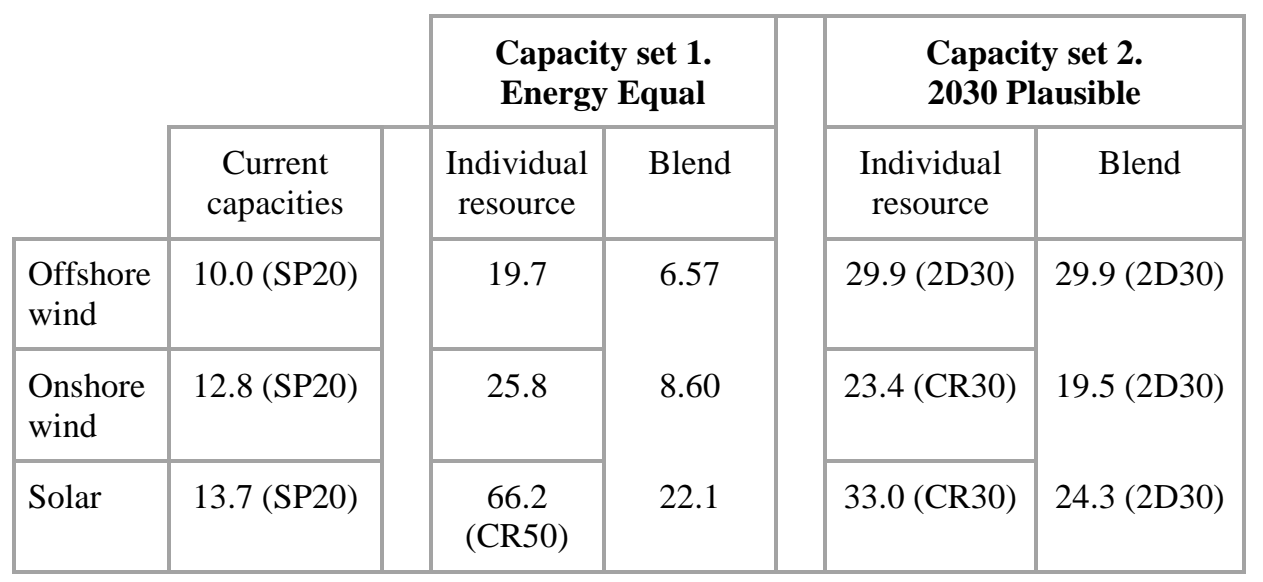

223

\subsection{Other considerations}

By drawing on modern reanalysis data, the results below emphasise inter-annual variability inherent to the current climate system and note related energy market policy risk and uncertainties. The analysis does not include the additional uncertainty which could arise with a changing climate. New generations of high resolution climate models can also be used to understand potential impacts of climate change on weather-dependent power system components, such as demand [41] renewable generation [42-47] and power system operation [48,49]. As energy policy evolves to better reflect inter-annual variability, consideration will also be needed to such growing understanding of longerterm changes.

The demand model is based on the recent system demand characteristic and is exposed to uncertainty with changes in electricity using technologies, which can be expected to increase with growing electrification of heat and transport. Such trends have the potential to both increase and fundamentally alter the timing of electricity demand. The daily aggregation of data, presented in section 3.1.3, addresses this to an extent. (Aggregation assumes a midnight to midnight day). Daily aggregation indicates the maximum potential benefit that could be achieved with in-day storage or comparable flexibility approaches. Global energy systems are seeing rapid development of demand response, energy storage and alternative flexibility approaches such as controlled two-way connection of 
electric vehicles (V2G or vehicle to grid). The greatest attention is being directed at in-day balancing or daily peak reduction [27] which ensures high utilisation of the capital invested.

It is not currently known how market and operational preferences will discriminate between nuclear and renewables as higher combined instantaneous system penetrations are reached. The system operator might wish to maintain nuclear generation for stability contribution increasing short-term curtailment of renewables. By contrast, an idealised market basis would give preference to renewables with their even lower marginal generation costs (as indicated by [32]). In turn, higher CFD agreements for new build nuclear could motivate higher negative price bidding and preferential operation. Accordingly, certain graphs show a 4.2GW threshold, representing the capacity of new nuclear operating under a CFD contract, expected to be operational by 2030.

The LDC approach brings value through illustrating a range of variability implications at a glance, however results are best interpreted as the limiting case, especially when considering curtailment. The approach neglects operational factors [50] which can contribute to relatively low levels of curtailment with current and near future renewables penetrations. More sophisticated modelling is needed to address plant start-up costs and ramping rate limits, as well as geographical power flow restrictions which are currently leading to renewable generation curtailment in the UK. In contrast, the net-load limits revealed by the LDC approach become increasingly significant as renewables deployment increases towards the capacity levels in our test cases.

\section{Results}

\subsection{Resource comparisons, Energy Equal contributions}

In this section we present results from the Energy Equal case described in section 2.3, with capacities detailed in Table 2. These capacities ensure that the long-term energy supplied by VRE is equal in each case. This allows the truest possible comparison of the influence of underlying variability.

Figure 2 shows the variation in annual resource capacity factors for the 36 year data range. Wind is seen to exhibit a striking inter-annual variability, notably greater than solar, or weather sensitive demand. The greatest wind energy is seen in 1986, while wind generation is lowest in 2010 alongside high demand. It is curious to note rare years, 1982, 1988 and 2005, where onshore and offshore wind anomalies show opposite signs.

Figure 3 examines the implications of the annual reference frame. When comparing years, it is common practice for energy researchers to adopt a calendar year basis, e.g. $[4,11,15,23,24]$. However, meteorologists would often group months into four seasons of three full months where weather is most typically consistent within each season - DJF, MAM, JJA, SON (December, January, February etc.) A calendar basis effectively splits each winter season across two separate years. Alongside the calendar year, we present a UK financial year (April to March) and an astronomical year (February to January). Of these, the UK financial year has the benefit of including a consistent meteorological winter (DJF) and summer (JJA). This reveals some notable differences, especially for wind generation, where the absolute inter-annual range is slightly reduced and 1986 is no longer a peak wind year; closer examination reveals that a 1986 calendar year combines contribution from two highwind winters. A new peak year of 1992 is seen for wind with both financial and astronomical framings. Other peaks are seen to shift years, dependent on the framing used. Whilst not influencing long term mean or variance, the alternate framings do reduce extremes, most significantly for wind power with max-min range reducing from $11.3 \%$ (calendar year) to $9.6 \%$ (financial year). 


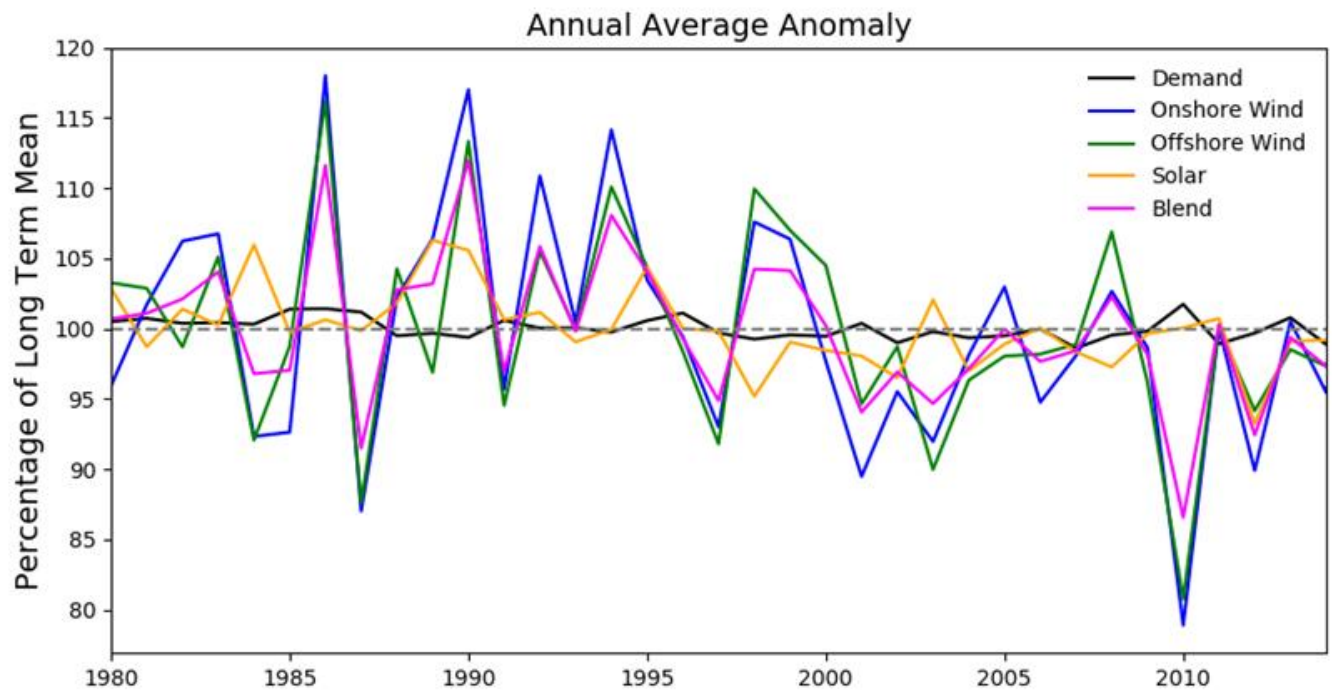

287

288

Figure 2, Variation in annual capacity factors, given calendar year basis

(a)
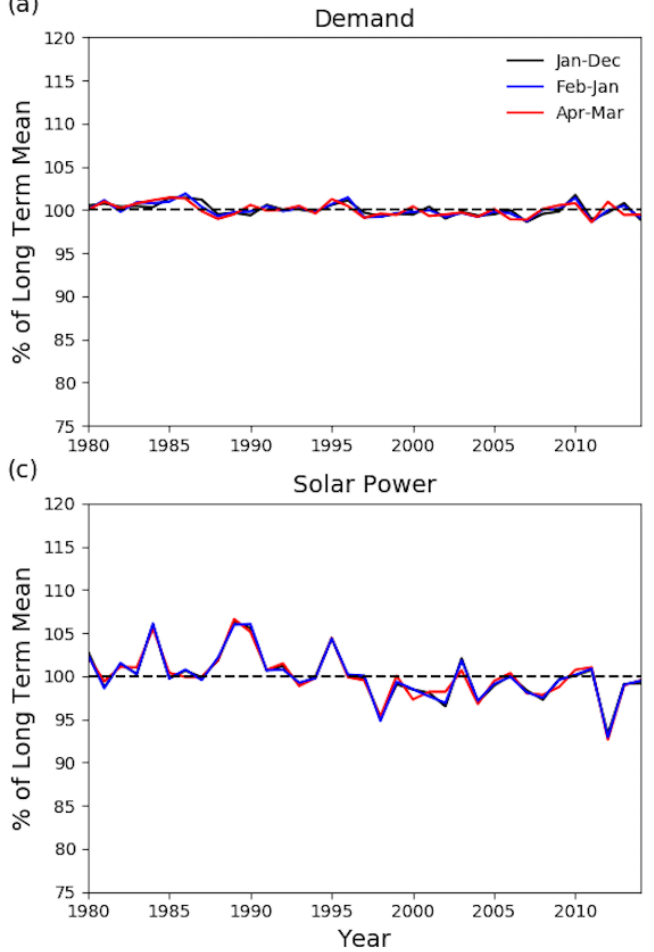

(b)

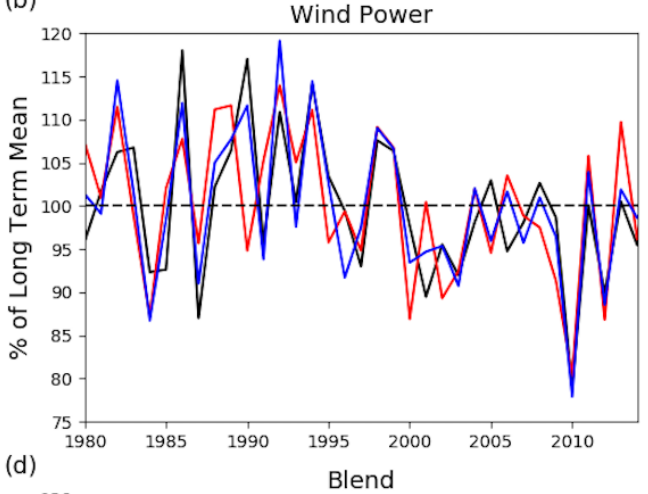

(d)

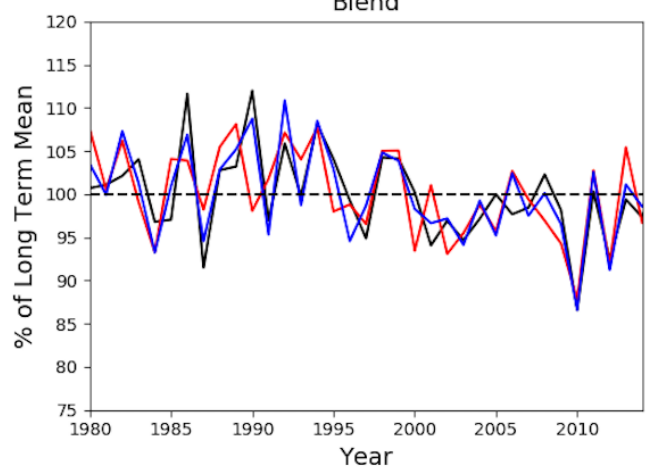

Figure 3, Variability in annual energy output, given three annual framings (year commencing in each case). Offshore and onshore wind are shown combined into a single wind time series. 
Pearson correlation values (defined as the ratio of the co-variance of the two variables to the product of their standard deviations [51]) between the annual (financial year) energy values shown in Figure 3 are presented in Table 3. Wind energy exhibits a weak negative correlation with demand, the only notable correlation which demonstrates any reasonable significance, with a $\mathrm{p}$ value of 0.05 . The weak significance values highlight the challenges in making such inter-annual comparisons with long-term datasets reduced to 36 data points. The alternate year framings were examined, though omitted here for brevity, revealing a further weakening of $p$ values.

Table 3. Comparison between inter-annual system influence for financial year basis. Stated values show Pearson's Correlation coefficient, with significance test p value outcomes in (...)

\begin{tabular}{|l|c|c|c|c|c|}
\hline & Demand & Onshore wind & Offshore wind & Solar & Blend \\
\hline Demand & & & & & \\
\hline Onshore wind & $\mathbf{- 0 . 3 3 ( \mathbf { 0 . 0 5 } )}$ & & & & \\
\hline Offshore wind & $-0.25(0.15)$ & $\mathbf{0 . 8 6}(<\mathbf{0 . 0 1})$ & & & \\
\hline Solar & $0.14(0.43)$ & $0.18(0.30)$ & $-0.06(0.74)$ & & \\
\hline Blend & $-0.27(0.11)$ & $\mathbf{0 . 9 7}(<\mathbf{0 . 0 1})$ & $\mathbf{0 . 9 2}(<\mathbf{0 . 0 1})$ & $0.24(0.15)$ & \\
\hline
\end{tabular}

\subsubsection{Full range LDC curves}

LDC analysis for a single example year is presented in Figure 4. Given the equal energy contributions assumed, the area between demand and each net-generation curve must be the same, long-term, though not necessarily within an individual year. Widely recognised concerns with the solar resource are immediately evident. The net solar curve shows no contribution to peak load at the left hand extreme, together with significant disruption to operating opportunity for long-run residual plant (seen at higher operating durations). There is also a need for curtailment, indicated by negative net load. The net wind curves display a more promising profile, with no clear difference seen between onshore and offshore wind. In this particular year, some contribution is made to reducing system peak load and despite a notable drop towards the right-hand end of the curve, no significant curtailment concerns arise. The net blend curve shows an initially surprising contribution to system peak, alongside a minor reduction to baseload disruption, implying an improvement in terms of system contribution to the single wind cases.

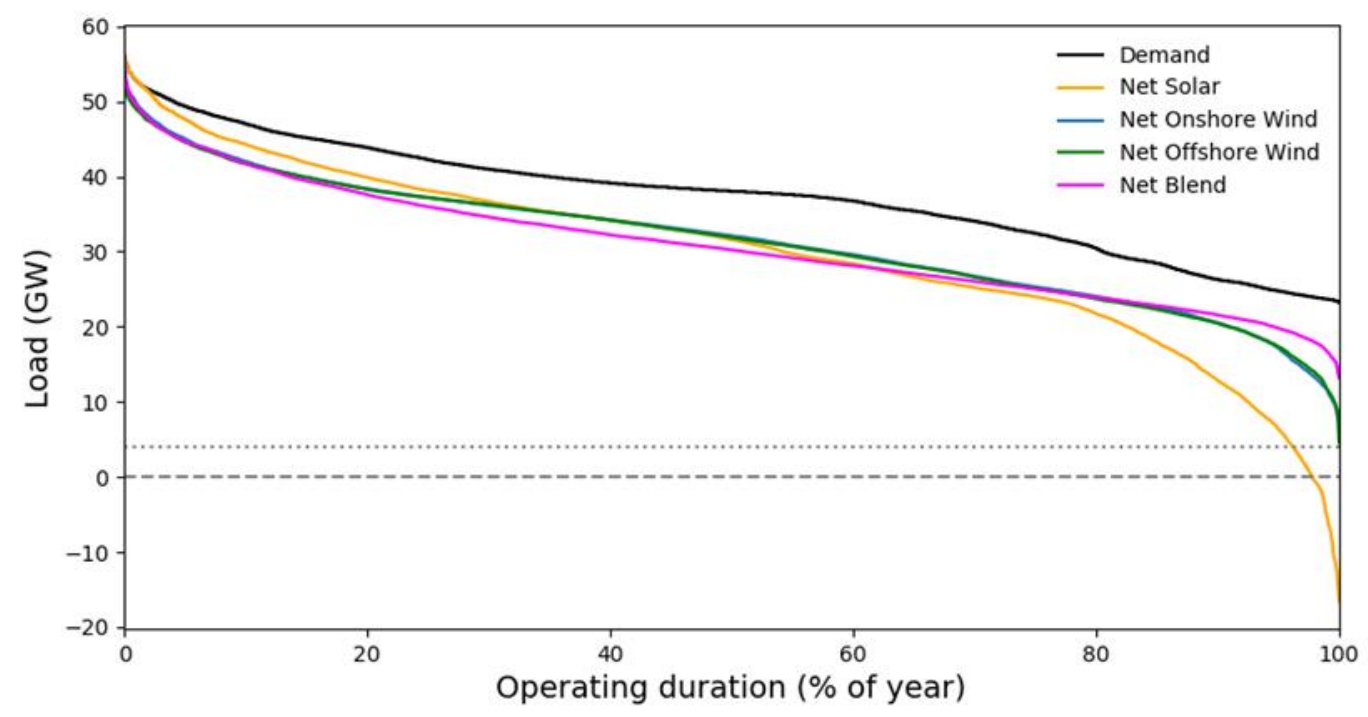




\subsubsection{Batch LDCs - Interannual variability}

322 In order to explore inter-annual variability, Figure 5 presents sets of 35 annual LDCs for each year in the reanalysis datasets. Only solar and onshore wind resources are shown, for clarity. Although much of the detail is still obscured by the amount of information on a single plot, some general trends can be seen. Both the onshore wind and solar result sets indicate greater year-to-year variability than the demand data set on its own. Caution is needed as the wind and solar curves here represent demand net resource, so reflect temperature and resource variability.

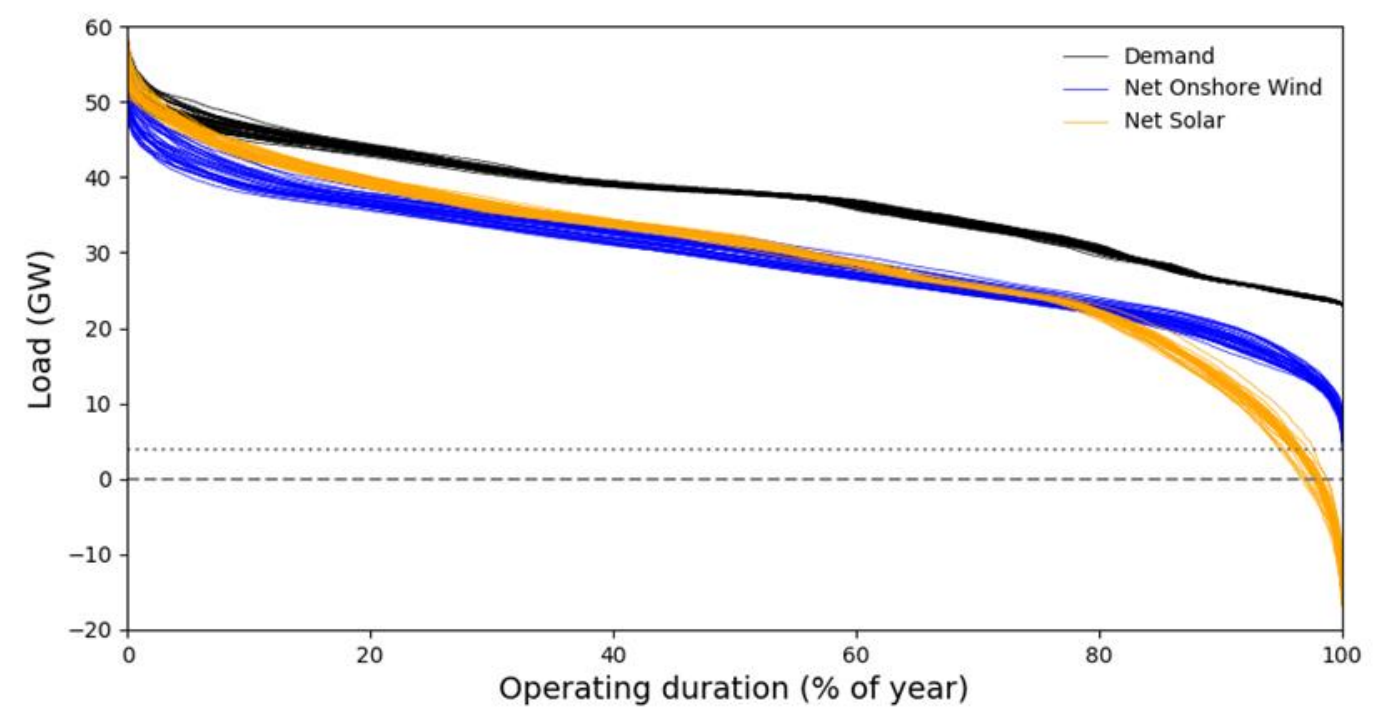

Figure 5. Annual LDCs for all years in reanalysis data set - Energy Equal case. Dotted line shows indicative new nuclear baseload.

331 A range of extreme years are identified in Table 4, given particular (a) annual energy and (b) power characteristics. With growing recognition of inter-annual variability's implications, it can be tempting to seek specific extreme years for 'stress testing' within energy system studies. For example, in a previous study we reported 1990 and 2010 were extreme weather years for UK demand influence, but 1986 and 2010 should be considered when wind supply is also a factor [4]. Similarly, [23] indicated that the weather years 2012 and 1989 were the most representative for considering power system operation at a European level. Both these studies adopted calendar year approaches. Table 4 reveals a need for caution here. Peak load events occur in different years to extreme annual energy values. VRE introduction further influences the extreme year, subject to capacity assumed. The choice of year framing also has a significant effect. By adopting a financial year and considering overall energy extremes, we find a different maximum demand year and further differences, including a change of year for every lowest energy case examined. 
(a) Total annual energy. Asterisk $(*)$ denotes years where this LDC serves as the extreme case across full operating duration range.

\begin{tabular}{|l|c|c|c|c|c|c|}
\hline & \multicolumn{2}{|c|}{ Year with highest total annual energy } & \multicolumn{2}{c|}{ Year with lowest total annual energy } \\
\hline & Calendar year & $\begin{array}{c}\text { Financial } \\
\text { year }\end{array}$ & $\begin{array}{c}\text { Astronomical } \\
\text { year }\end{array}$ & Calendar year & $\begin{array}{c}\text { Financial } \\
\text { year }\end{array}$ & $\begin{array}{c}\text { Astronomical } \\
\text { year }\end{array}$ \\
\hline Demand & 2010 & $1985 / 86$ & $1986 / 87^{*}$ & 2007 & $2011 / 12$ & $2011 / 12$ \\
\hline Net solar & $2010^{*}$ & $2012 / 13$ & $1986 / 87^{*}$ & $2014^{*}$ & $1989 / 90$ & $2011 / 12$ \\
\hline $\begin{array}{l}\text { Net onshore } \\
\text { wind }\end{array}$ & $2010^{*}$ & $2010 / 11^{*}$ & $2010 / 11^{*}$ & $1990^{*}$ & $1988 / 89$ & $1992 / 93$ \\
\hline $\begin{array}{l}\text { Net offshore } \\
\text { wind }\end{array}$ & $2010^{*}$ & $2010 / 11^{*}$ & $2010 / 11^{*}$ & $1990^{*}$ & $1994 / 95$ & $1998 / 99$ \\
\hline Net blend & $2010^{*}$ & $2010 / 11^{*}$ & $2010 / 11^{*}$ & $1990^{*}$ & $1988 / 89$ & $1992 / 93$ \\
\hline
\end{tabular}

(b) Long term load extremes

\begin{tabular}{|l|c|c|c|c|c|c|c|c|}
\hline & $\begin{array}{c}\text { Max } \\
\text { load } \\
(\mathrm{GW})\end{array}$ & $\begin{array}{c}\text { Calendar } \\
\text { year }\end{array}$ & $\begin{array}{c}\text { Financial } \\
\text { year }\end{array}$ & $\begin{array}{c}\text { Astronomical } \\
\text { year }\end{array}$ & Min load & $\begin{array}{c}\text { Calendar } \\
\text { year }\end{array}$ & $\begin{array}{c}\text { Financial } \\
\text { year }\end{array}$ & $\begin{array}{c}\text { Astronomical } \\
\text { year }\end{array}$ \\
\hline Demand & 60.9 & 1987 & $1986 / 87$ & $1986 / 87$ & 23.0 & Multiple & Multiple & Multiple \\
\hline Net solar & 60.9 & 1987 & $1986 / 87$ & $1986 / 87$ & -17.0 & 2009 & $2009 / 10$ & $2009 / 10$ \\
\hline $\begin{array}{l}\text { Net } \\
\text { onshore } \\
\text { wind }\end{array}$ & 57.8 & 1982 & $1981 / 82$ & $1981 / 82$ & 4.0 & 1988 & $1988 / 89$ & $1988 / 89$ \\
\hline $\begin{array}{l}\text { Net } \\
\text { offshore } \\
\text { wind }\end{array}$ & 56.3 & 1985 & $1984 / 85$ & $1984 / 85$ & 4.4 & 1983 & $1983 / 84$ & $1983 / 84$ \\
\hline Net blend & 56.5 & 1982 & $1981 / 82$ & $1981 / 82$ & 9.1 & 1996 & $1996 / 97$ & $1996 / 97$ \\
\hline
\end{tabular}

349 Further analysis of the LDC batches has been carried out to investigate the spread between years, with 350 conventional annual LDCs presented in Figure 6 panels (a) and (c). Panels (b) and (d) keep the same y axis as (a) and (c), respectively, but show the horizontal separation for each capacity level between the years with the shortest and longest operating opportunity. Black dashed arrows have been added for two example load levels to translate the spread in LDC curves from panel (a) to the separation shown at the same level in panel (b).

Onshore wind shows the highest spread between years, a little above that from offshore wind. By contrast, the net-solar line indicates the lowest inter-annual variability, reducing the spread at any given capacity level below that seen for demand alone. This comes at the expense of a greater

358 disruption to the opportunity for longer running residual plant. At this installed capacity, solar leads to 359 hours where negative load is seen with a high, relative inter-annual variability. Blending resources 360 offers multiple benefits, by reducing inter-annual variability further below offshore wind, while simultaneously smoothing the disruption to residual plant. 
(a)
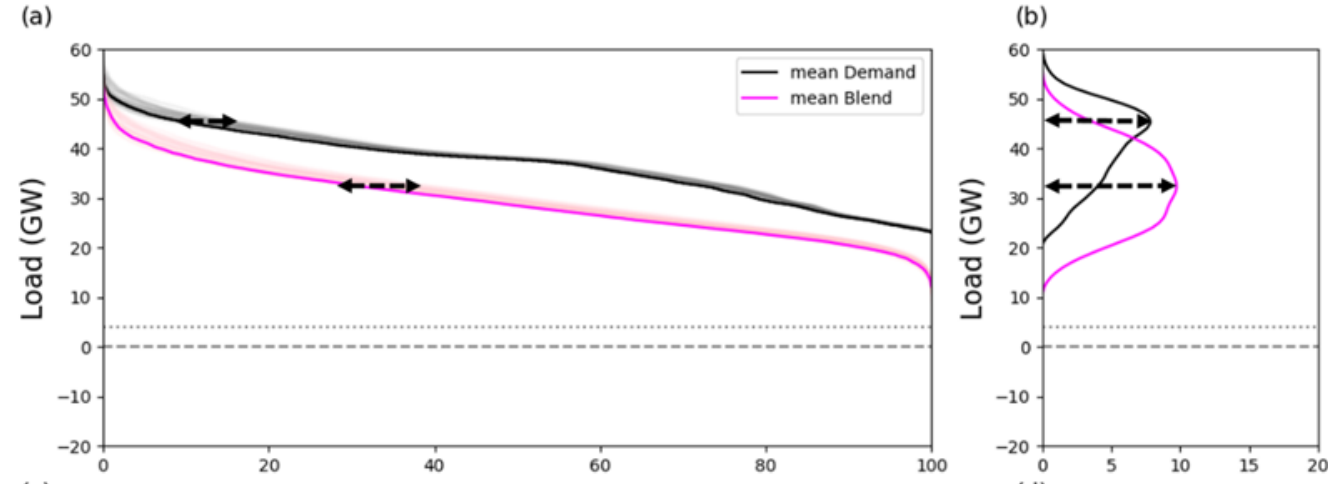

(c)
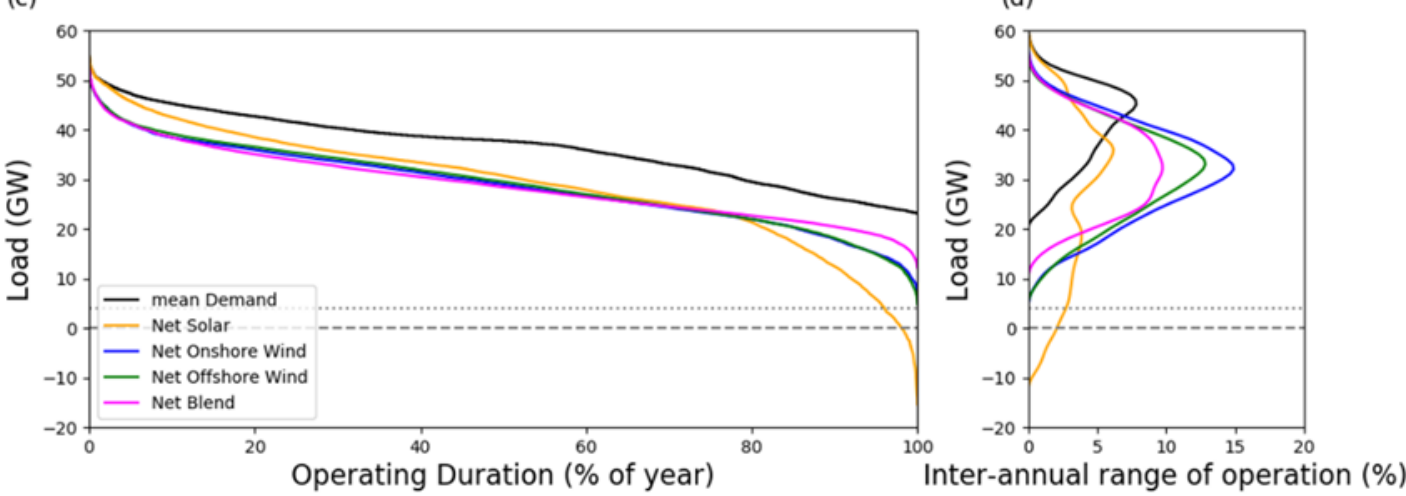

Figure 6. 35 year LDCs and analysis of inter-annual spread-Energy Equal case. In panels (a) and (c) solid lines represent the LDC for 2011, the most typical single year. Panel (a) also includes shading to show the range exhibited by all annual LDCs. Black, dashed arrows on panels $(a)$ and $(b)$ show how the horizontal spread translates to the inter-annual range seen in panels $(b)$ and $(d)$. Dotted line shows indicative new nuclear baseload.

\subsubsection{Daily smoothing, full range LDCs}

368 Widespread attention is being given across the energy industry to the development and implementation of energy storage and other flexibility approaches. (Flexibility is used as a collective term below to include storage.) Much of this is explicitly linked to the challenges of integrating variable renewable generation. This brings a potential contradiction for the analysis here, which seeks to identify the fundamental constraints brought by meteorological factors, without introducing the other uncertainties inherent in much techno-economic modelling. Accordingly, we have tested daily aggregation to scope a limiting case for flexibility introduction, without needing to make assumptions about economic potential. This is consistent with the great majority of currently proposed solutions, which are best suited to daily, or more frequent, operation. Figure 7 presents long-term LDCs (1980 2015) for the Energy Equal capacity set, using data aggregated to daily values. The daily match between each resource and demand represents the limiting case that a perfectly operated store could deliver if sized for maximum daily imbalance. 

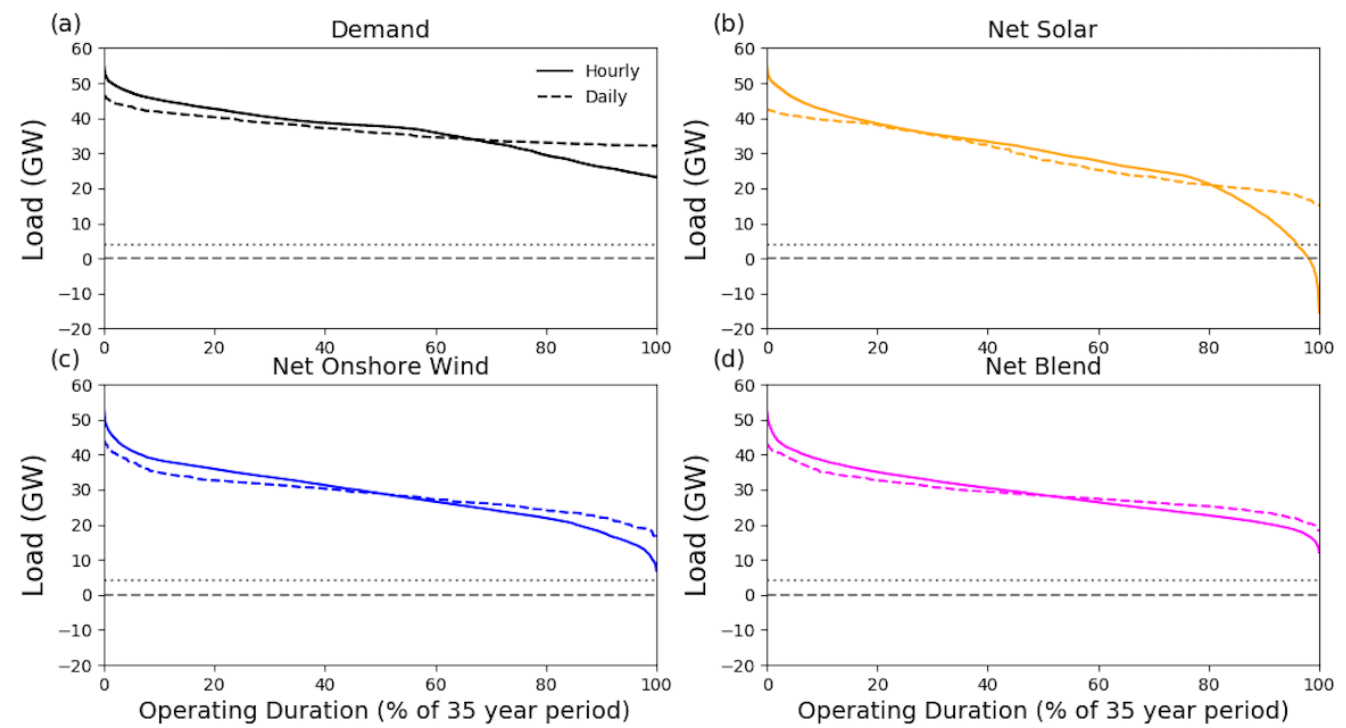

Figure 7. Hourly and daily smoothed 35 year LDC for Energy Equal case. Dotted line shows indicative new nuclear baseload.

383 It can be seen from Figure 7 (a) that adding flexibility to demand alone, provides a significant advantage, both reducing peak load and expanding the residual operating opportunity at high load factors. The greatest benefit is seen with the solar resource (b), showing a slight additional reduction in system peak and a dramatic increase in operating opportunity for baseload plant. However, the vertical gap between hourly and daily lines informs the power capacity of store that would be needed. The improvement seen for solar requires close to $30 \mathrm{GW}$ of storage capacity. By contrast the blended case (d) shows a more subtle, but more promising improvement. A gap is seen between the daily and hourly curves across a wide spread of operating durations, indicating potential for high storage utilisation. Further, the capacity contribution is similar for both peak reduction and baseload improvement, requiring a more modest power capacity of storage, no greater than $10 \mathrm{GW}$.

\subsection{Renewable expansion}

This section examines the 2030 Plausible capacity assumptions, derived in section 2.3 (individual capacities of $33.0 \mathrm{GW}$ solar, $23.4 \mathrm{GW}$ onshore wind, $29.9 \mathrm{GW}$ offshore wind, and a blended case comprising $24.3 \mathrm{GW}$ solar, $19.5 \mathrm{GW}$ onshore wind, $29.9 \mathrm{GW}$ offshore wind). The individual capacities for solar and onshore wind are lower than those assessed above, whereas offshore wind is now higher. The blended capacity here is considerably higher than the individual resource cases. 
(a)

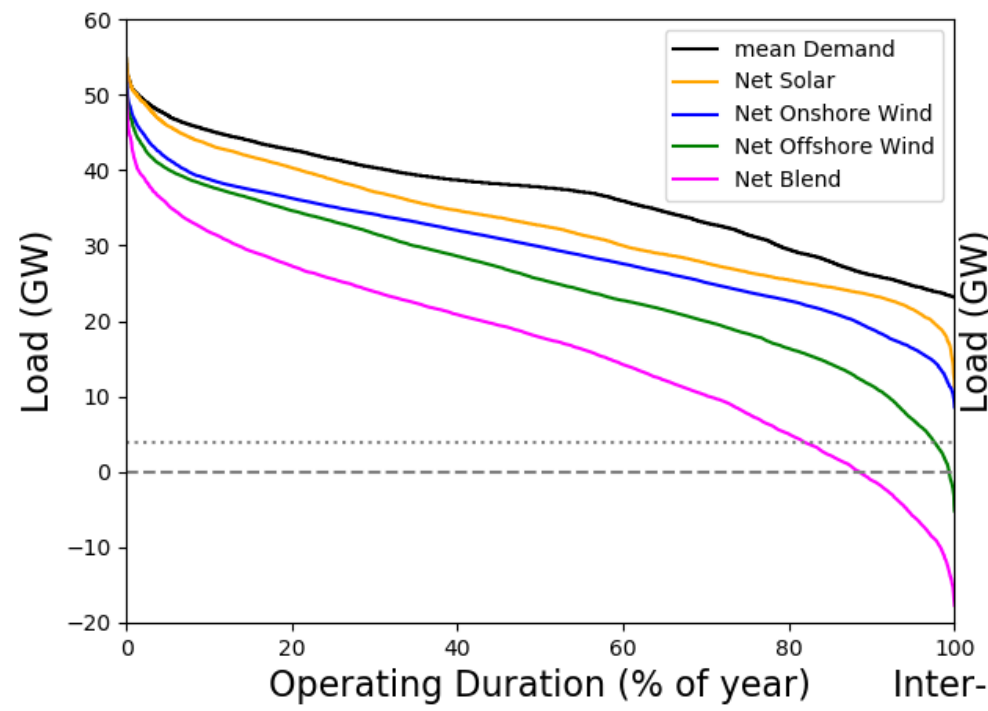

(b)

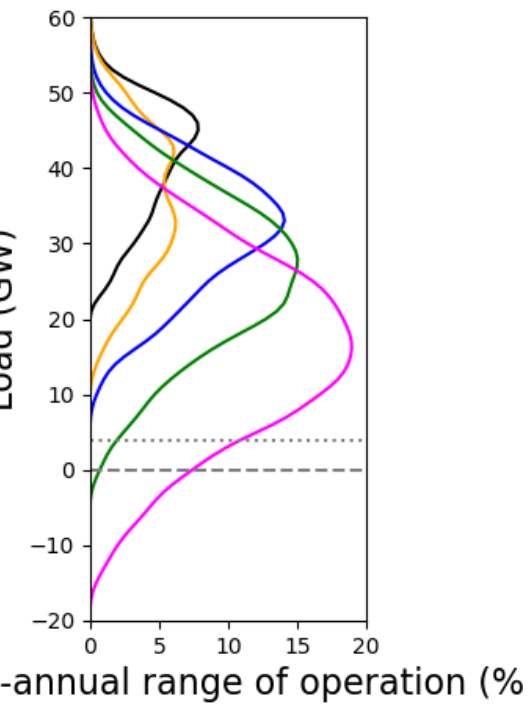

Figure 8. LDC inter-annual spread analysis - 2030 Plausible capacities (a) Single year typical LDC (2011) and (b) spread analysis. Dotted line shows indicative new nuclear baseload.

403 The increased capacity of offshore wind and the blended case contributes to emerging challenges, with Figure 8 showing a significant reduction in the operating opportunity for residual baseload plant. The blended case indicates that substantial curtailment could be expected and from panel (b) that there would be a sizeable swing from one year to another in both curtailment level and baseload disruption. The horizontal dotted line reflects a possible $4.2 \mathrm{GW}$ of new nuclear plant and a $10 \%$ horizontal range in the operating opportunity is seen at this level. This represents a range to either side of the $80 \%$ value shown in panel (a). Given uncertainty in market preference between renewable generation and new nuclear this could translate either as lost operating opportunity for nuclear or increased renewable curtailment. From Figure 9 (d) it can be seen that daily smoothing provides a modest improvement but does not eliminate the need for curtailment.
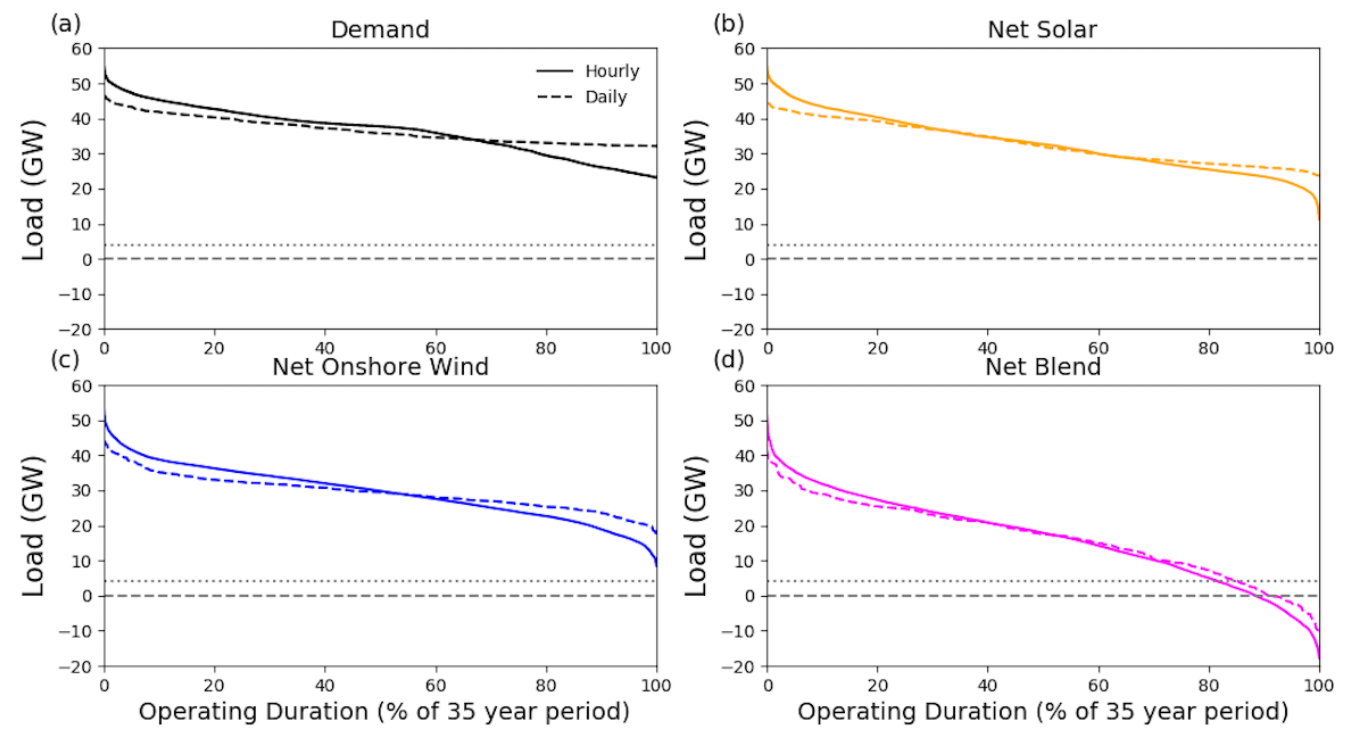

414 Figure 9. Hourly and daily smoothed 35 year LDC for 2030 plausible capacities. Dotted line shows indicative new nuclear 415 baseload. 
Annual peaks for demand only and Energy Equal net-renewables cases are shown in Figure 10. There is a large inter-annual variability in peak demand, with a range of $51.1 \mathrm{GW}$ to $60.9 \mathrm{GW}$. All these events occur during the darkness peak in winter when there is no contribution from solar. As a result, lines for demand and solar are coincident throughout the entire range. Wind generation leads to a reduction in the peak residual demand in all years, though this varies widely. For example, for the 1985-86 winter the peak is reduced by $6.1 \mathrm{GW}$, in comparison to only $0.7 \mathrm{GW}$ for the 2013-14 winter, albeit a lower reduction from a lower peak. Peak reduction is broadly similar for the onshore, offshore and blended resources. However, certain anomalous years invite further investigation to understand the large-scale meteorological drivers of peak residual demand as the capacity and ratio of offshore and onshore wind changes.

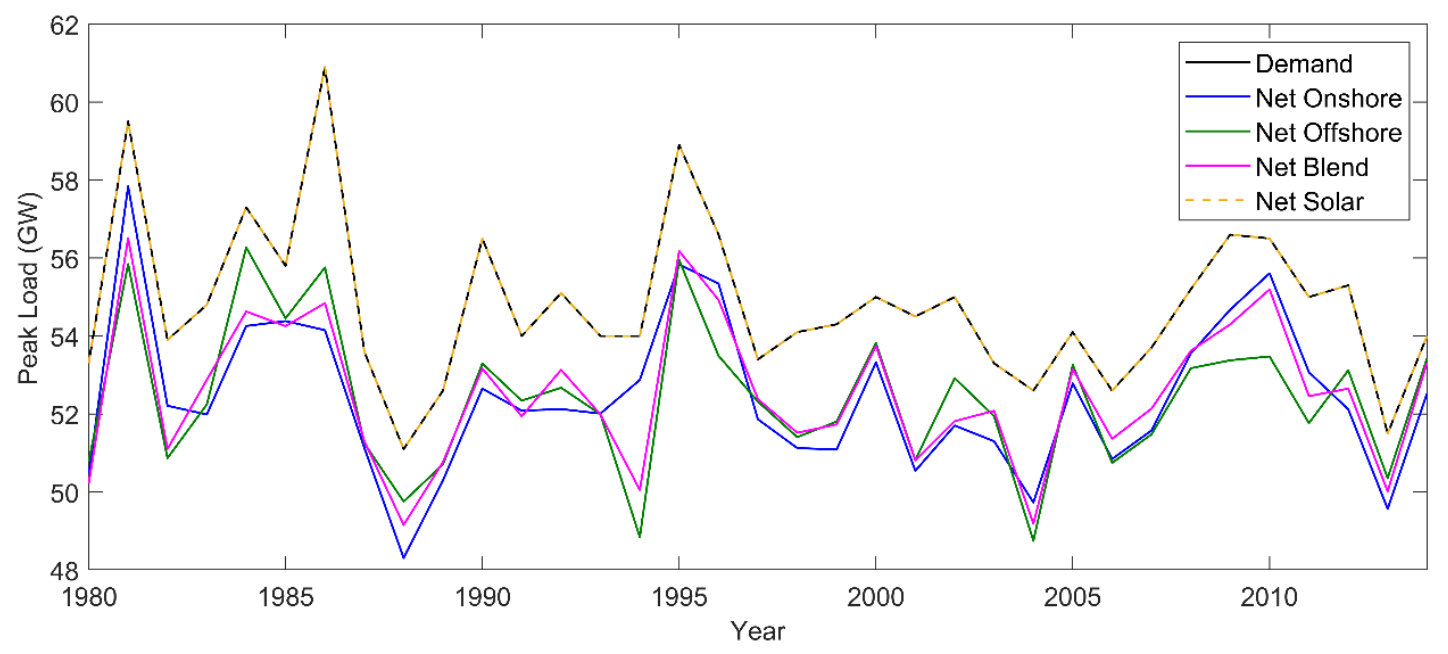

Figure 10, Long term variation in annual peak demand / residual demand (Energy Equal case, financial year basis)

This section explores the occurrence of demand exceeding supply if a consistent long-term generating capacity is set based on an average Loss of Load Expectation (LOLE) of three hours per year (as outlined in Section 1). With 35 years in the data set, this translates to 105 hours in total. Table 5 presents the capacity level that would be exceeded for 105 hours given Energy Equal capacity assumptions. Figure 11 presents the number of hours in each year that these capacity levels would be exceeded. Consistent with the approach used throughout, this describes what would be seen if historic weather conditions aligned with the assumed capacity assumptions. This should not be directly compared with the UK System Operator's Average Cold Spell method, which applies a statistical sampling approach in combination with a demand model to establish a winter peak demand with a 50 per cent chance of being exceeded as a result of weather variation alone [52].

Table 5 Capacities required to maintain long-term LOLE of 3 hours per year

\begin{tabular}{|l|c|}
\hline & $\begin{array}{c}\text { Capacity } \\
\text { requirement (GW) }\end{array}$ \\
\hline Demand & 55.9 \\
\hline Net onshore wind & 52.7 \\
\hline Net offshore wind & 52.4 \\
\hline Net blend & 52.9 \\
\hline
\end{tabular}

Taking a long-term average LOLE threshold leads to a large range in the number of hours of capacity exceedance in any given year, as seen in Figure 11. This is particularly the case for demand only (27 hours in 1986-87 whereas in many others it can be zero). Initially it appears surprising that renewable 
based cases demonstrate a lower range. However, closer analysis of the demand only data has shown that peaks in 1981-82, 1984-85 and 1986-87 include multi day events. By contrast, introducing renewables decreases the number of multi-day events, with the presence of wind acting to reduce persistence and smooth out the combined effect of wind supply and demand.

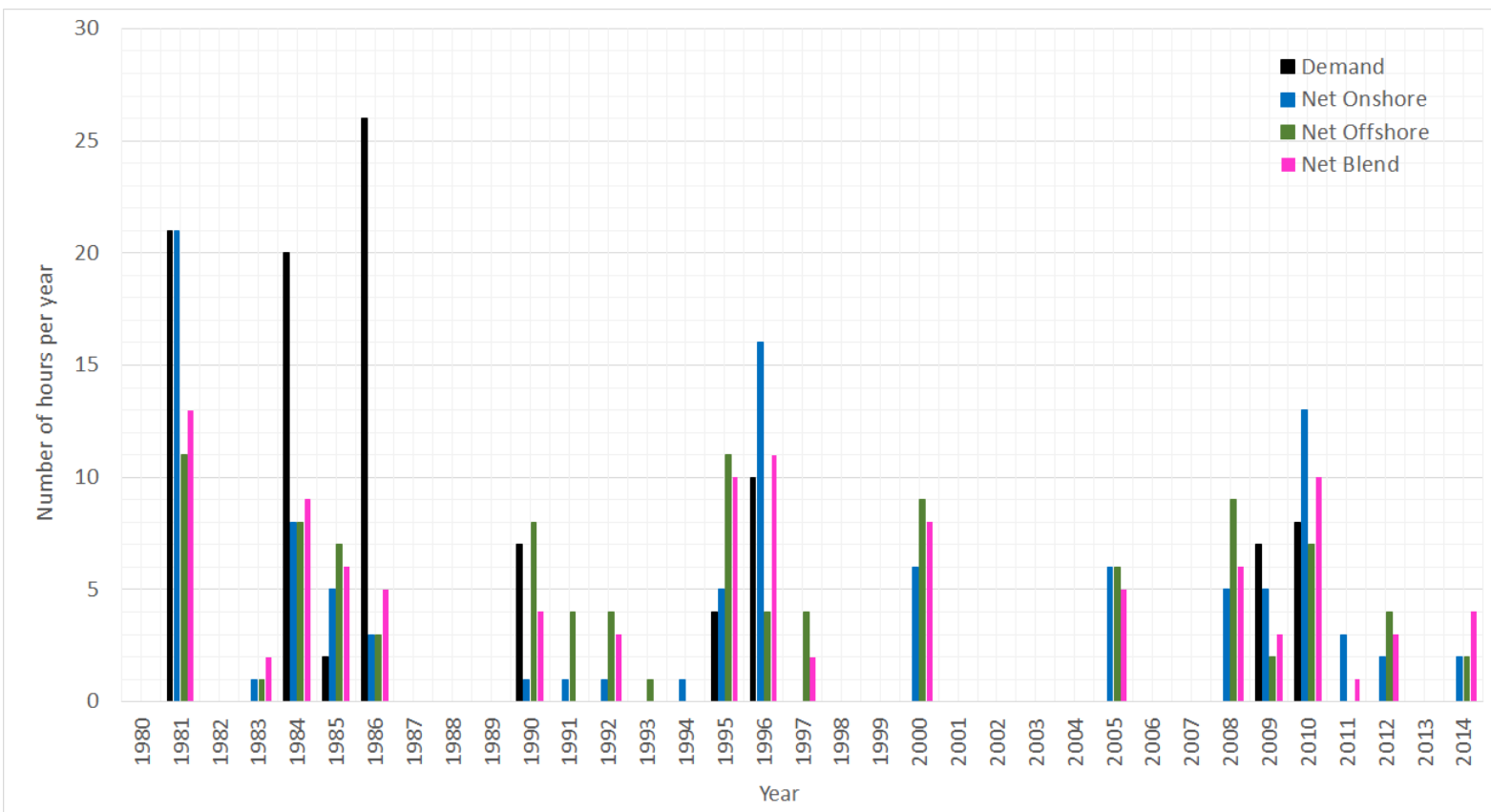

Figure 11, Annual loss of load, given total system capacity required to achieve long term average of 3 hours.

\section{Discussion}

Variability of renewable power generation has been represented with growing sophistication in energy system modelling studies to reflect the technical and economic challenges of operation and / or investment. Widespread uncertainty is seen, though, especially when multiple studies are compared, with particular exposure to economic uncertainties. One consequence can be to obscure the influence of fundamental weather characteristics. There is a need for approaches which give policy makers greater visibility of underlying meteorological influences, in a manner which can be distinguished from other social, technical and economic assumptions. Inter-annual variability is especially significant in this context. Alongside the recognised need for sophisticated modelling, there is a role for relatively simple energy system assessment approaches which can highlight sensitivity to meteorological drivers and allow closer scrutiny of weather influence.

Energy applications of meteorological approaches have grown in sophistication alongside the growth of renewable generation. One notable advance has been the increasing use of meteorological, reanalysis datasets. The analysis presented above adds weight to our earlier argument [4] that energy modelling studies should seek to use the longest feasible range of weather data and that this must span multiple years, more recently supported by multiple studies including [16,23,24]. Such practice is increasing but not yet widespread, as it can be attractive to use single years for ease of computation and data representation. Stress testing with just a few extreme years can offer a compromise but must be approached with caution. We are not aware of any previous consideration of the implications of annual reference frame. Our exploration has shown that care is needed in considering the annual reference basis and the specific research question if selecting such sample years. Clarity can be improved by choosing an annual frame that reflects meteorological factors. By example, a UK financial year corresponds to approximately complete 'meteorological seasons' whereas a calendar year splits the meteorological winter season (DJF). 
The analysis above suggests a higher value for solar generation in temperate climates than previously recognised. It has been widely argued that solar energy brings little system value in high latitude countries, such as the UK, where electricity demand is highest during cold, dark, winter evenings. By contrast, a load duration perspective emphasises the likelihood that solar generation is available when wind generation is not. This is shown by the difference between the wind only and blended cases in Figure 6. When added to a system that already has moderate levels of wind generation, there is greater operating opportunity for new solar than for continuously operating plant such as baseload nuclear. Similarly, a mix of wind and solar offers greater opportunity for other plant than an equal energy contribution from wind alone. Solar output also exhibits a much lower inter-annual variability than wind, with little or no correlation seen with demand or wind. A sizeable solar contribution can therefore go some way to mitigating the inter-annual variability of wind supply.

Electricity system decarbonisation is bringing new challenges for energy market design. Section 1 noted an ongoing debate whether energy only markets can ensure supply adequacy, or supplementary, power linked, capacity assurance mechanisms are needed. Inter-annual variability will bring different implications for the UK's CFD and Capacity Mechanism schemes, set to grow with further, planned increases in renewable generation:

- Figure 8 indicates that certain mid-merit plant could face inter-annual load factor variation above 15\%. For plausible 2030 installed capacities, the blended case shows a maximum 19\% inter-annual range in operating opportunity for residual plant with a typical load factor of $60 \%$. This contrasts with a 5\% range for the no renewable case and would represent a significant economic uncertainty for plant with high capital costs. This would also be reflected as a difference in annual CFD payments, exposing such schemes to criticism for being too generous in years when output is high.

- Annual peak demand is seen to vary by up to $10 \mathrm{GW}$ for the demand only case in Figure 10 (using Energy Equal capacity assumptions). This range represents an inherent risk with the Capacity Mechanism. Any threshold that ensures robust adequacy across all years will reward plant that appears unnecessary in many or most years. The demand only variation here is entirely a feature of temperature variability. It is slightly surprising that introduction of renewables reduces the interannual range in residual demand to approximately $6.5 \mathrm{GW}$ (blended case). This suggests renewables can reduce Capacity Mechanism uncertainty. Our demand model should be treated as indicative, here; the model is calibrated with system demand recorded across 2006-2015 and demand-side energy using technologies are changing rapidly. Any increase in the adoption of electrical heating would be expected to amplify the sensitivity to temperature.

As well as assuring physical generating capacity, it is common system design practice to accept some level of lost load each year. Once again, inter-annual variability brings a risk for the perceived effectiveness of energy policy / system planning. Figure 11 estimates the number of weather influenced loss of load events that would have been experienced each year given a long term average of 3 hours LOLE per year. Surprisingly, the highest number of events in any individual year comes with the demand only case. The blended renewables case is seen to reduce the severity of system stress events. In mature systems such as the UK, 'lost load' is very unlikely to mean uncontrolled loss of supply, but instead suggests periods where the system operator can call on certain non-routine measures to maintain system balance. This reflects a balance between the cost implication of such actions and the cost of retaining rarely used generating plant. Detailed analysis suggests that years with higher LOLE are driven by persistent weather events. Increasing wind generation leads to a reduced likelihood of persistent stress events as low temperatures do not coincide exactly with low wind speed periods.

\section{Conclusions}

In seeking the policy implications of inter-annual renewable energy variability, we have chosen to apply a simple modelling framework. This has allowed us to concentrate specifically on the behaviour and implications of the underpinning weather characteristics, which are widely recognised to have a growing significance for global energy systems. We note and fully encourage the increasing adoption of long-term weather data sets within studies that use more sophisticated energy system models. 
However, we argue that significant value remains in using more parsimonious approaches in parallel.

528 Care is needed not to lose sight of weather fundamentals which can be masked by other highly

529 uncertain assumptions of technologically rich and mathematically sophisticated models, not least

530 uncertain economic factors such as plant cost assumptions and financial discount rates.

531 Although inter-annual variability has seen recent, growing recognition in energy system research, it

532 has commonly been neglected in policy discourse where long-term average approaches are widely

533 used. The significance of inter-annual variability will increase markedly in energy systems that deploy

534 greater electrification of heating alongside higher levels of variable renewable energy. This suggests a need to consider which market actors are best placed to manage long term variability and view revenues across multiple years rather than single annual accounting periods. This needs to be reflected in the design of electricity markets and in any related incentive mechanisms.

- The operating opportunity for mid-merit and baseload generation will vary substantially from one

539 year to another. This could be highly problematic where sole reliance is placed on energy payments to

540 cover fixed costs.

- Consideration of capacity assurance approaches needs to better reflect inter-annual variability as the characteristics of demand net renewables will deviate increasingly from absolute demand

- The operating opportunity for energy storage also presents problematic inter-annual variability. This suggests that energy storage cannot be economically deployed to absorb all curtailment that could otherwise occur in a high renewable system.

546 Perhaps more surprisingly, notable benefits are seen from increasing the level of solar generation 547 when long-term variability is considered. Solar energy displays significantly lower inter-annual 548 variability and little or no correlation with wind generation, as well as a gap-filling role when shorter 549 timescales are addressed. Blends of renewables which include a sizable solar contribution benefit 550 from this reduced inter-annual variability and show less disruption to the operating opportunity for other generating plant requiring high load factors.

The need for energy policy approaches to reflect the increasing impact of weather variability can be supported by growing sophistication in meteorological methods. While comprehensive weather records span mere decades and climate change introduces new unknowns, studies drawing from stateof-the-art, high-resolution climate models are expected to offer increasing insights. Our analysis emphasises the value of a diverse resource mix when moving to a high renewable system, with solar energy bringing benefits that might seem surprising for a country such as the UK, with a poor solar resource and high winter energy demand. Above all, an increased recognition of inter-annual variability is needed when addressing energy market design and any incentive mechanisms deployed.

\section{Acknowledgements}

561 While supporting the new analysis presented above, Bloomfield has been funded by the European 562 Union's Horizon 2020 research and innovation programme under grant agreement number 776787.

563 Drew is funded by a NERC NPIF fellowship, grant number NE/RE013276/1. The work synthesises 564 and builds on data and methods developed in a series of earlier studies. We would like to thank Dr 565 Dirk Cannon for his efforts in initial development and validation of the wind energy model and reiterate our thanks to National Grid and the UK Meteorological Office for their support to components of the enabling research.

\section{Data Availability}

569 The data used in this study are freely available for download from the University of Reading Research 
572

[1] M. Davies, The relationship between weather and electricity demand, Proc. IEE Part C Monogr. 106 (1959) 27. doi:http://dx.doi.org/10.1049/pi-c.1959.0007.

[2] A. Baker, D. Bunn, E. Farmer, Load forecasting for scheduling generation on a large interconnected system, Wiley, Chichester, 1985.

[3] J.W. Taylor, R. Buizza, Using weather ensemble predictions in electricity demand forecasting, Int. J. Forecast. (2003). doi:10.1016/S0169-2070(01)00123-6.

[4] H.C. Bloomfield, D.J. Brayshaw, L.C. Shaffrey, P.J. Coker, H.E. Thornton, Quantifying the increasing sensitivity of power systems to climate variability, Environ. Res. Lett. 11 (2016). doi:10.1088/1748-9326/11/12/124025.

[5] H.E. Thornton, B.J. Hoskins, A.A. Scaife, The role of temperature in the variability and extremes of electricity and gas demand in Great Britain, Environ. Res. Lett. (2016). doi:10.1088/1748-9326/11/11/114015.

[6] ENTSOE-E, ENTSO-E Transparency Platform, (2019). https://transparency.entsoe.eu/ (accessed March 19, 2019).

[7] D.J. Brayshaw, C. Dent, S. Zachary, Wind generation's contribution to supporting peak electricity demand-meteorological insights, Proc. Inst. Mech. Eng. Part O J. Risk Reliab. 226 (2012) 44-50. doi:10.1177/1748006X11417503.

[8] M.L. Kubik, D.J. Brayshaw, P.J. Coker, J.F. Barlow, Exploring the role of reanalysis data in simulating regional wind generation variability over Northern Ireland, Renew. Energy. 57 (2013) 558-561. doi:10.1016/j.renene.2013.02.012.

[9] D. Drew, D. Cannon, D. Brayshaw, J. Barlow, P. Coker, The Impact of Future Offshore Wind Farms on Wind Power Generation in Great Britain, Resources. 4 (2015) 155-171. doi:10.3390/resources4010155.

[10] C.R. Ely, D.J. Brayshaw, J. Methven, J. Cox, O. Pearce, Implications of the North Atlantic Oscillation for a UK-Norway Renewable power system, Energy Policy. 62 (2013) 1420-1427. doi:10.1016/j.enpol.2013.06.037.

[11] S. Pfenninger, I. Staffell, Long-term patterns of European PV output using 30 years of validated hourly reanalysis and satellite data, Energy. (2016). doi:10.1016/j.energy.2016.08.060.

[12] D. Hdidouan, I. Staffell, The impact of climate change on the levelised cost of wind energy, Renew. Energy. (2017). doi:10.1016/j.renene.2016.09.003.

[13] E. Sharp, P. Dodds, M. Barrett, C. Spataru, Evaluating the accuracy of CFSR reanalysis hourly wind speed forecasts for the UK, using in situ measurements and geographical information, Renew. Energy. (2015). doi:10.1016/j.renene.2014.12.025.

[14] J. Wohland, N.E. Omrani, D. Witthaut, N.S. Keenlyside, Inconsistent Wind Speed Trends in Current Twentieth Century Reanalyses, J. Geophys. Res. Atmos. (2019). doi:10.1029/2018JD030083.

[15] L.C. Cradden, F. McDermott, L. Zubiate, C. Sweeney, M. O’Malley, A 34-year simulation of wind generation potential for Ireland and the impact of large-scale atmospheric pressure patterns, Renew. Energy. (2017). doi:10.1016/j.renene.2016.12.079.

[16] I. Staffell, S. Pfenninger, The increasing impact of weather on electricity supply and demand, Energy. 145 (2018) 65-78. doi:10.1016/j.energy.2017.12.051.

[17] D.J. Cannon, D.J. Brayshaw, J. Methven, P.J. Coker, D. Lenaghan, Using reanalysis data to quantify extreme wind power generation statistics : A 33 year case study in Great Britain, Renew. Energy. 75 (2015) 767-778. doi:10.1016/j.renene.2014.10.024.

[18] M.M. Rienecker, M.J. Suarez, R. Gelaro, R. Todling, J. Bacmeister, E. Liu, M.G. Bosilovich, 
S.D. Schubert, L. Takacs, G.K. Kim, S. Bloom, J. Chen, D. Collins, A. Conaty, A. Da Silva, W. Gu, J. Joiner, R.D. Koster, R. Lucchesi, A. Molod, T. Owens, S. Pawson, P. Pegion, C.R. Redder, R. Reichle, F.R. Robertson, A.G. Ruddick, M. Sienkiewicz, J. Woollen, MERRA: NASA's modern-era retrospective analysis for research and applications, J. Clim. (2011). doi:10.1175/JCLI-D-11-00015.1.

[19] L. Bengtsson, S. Hagemann, K.I. Hodges, Can climate trends be calculated from reanalysis data?, J. Geophys. Res. D Atmos. (2004). doi:10.1029/2004JD004536.

[20] R. Gross, P. Heptonstall, D. Anderson, T. Green, M. Leach, J. Skea, The Costs and Impacts of Intermittency: An assessment of the evidence on the costs and impacts of intermittent generation on the British electricity network, UK Energy Research Centre, 2006. http://www.ukerc.ac.uk/publications/the-costs-and-impacts-of-intermittency.html.

[21] P. Heptonstall, R. Gross, F. Steiner, The costs and impacts of intermittency - 2016 update, UK Energy Research Centre, 2017. http://www.ukerc.ac.uk/publications/the-costs-and-impacts-ofintermittency-2016-update.html.

[22] J.P. Deane, A. Chiodi, M. Gargiulo, B.P. Ó Gallachóir, Soft-linking of a power systems model to an energy systems model, Energy. 42 (2012) 303-312. doi:10.1016/j.energy.2012.03.052.

[23] S. Collins, P. Deane, B. Ó Gallachóir, S. Pfenninger, I. Staffell, Impacts of Inter-annual Wind and Solar Variations on the European Power System, Joule. 2 (2018) 2076-2090. doi:10.1016/j.joule.2018.06.020.

[24] M. Zeyringer, J. Price, B. Fais, P.H. Li, E. Sharp, Designing low-carbon power systems for Great Britain in 2050 that are robust to the spatiotemporal and inter-annual variability of weather, Nat. Energy. 3 (2018) 395-403. doi:10.1038/s41560-018-0128-x.

[25] M. McPherson, N. Johnson, M. Strubegger, The role of electricity storage and hydrogen technologies in enabling global low-carbon energy transitions, Appl. Energy. 216 (2018) 649661. doi:10.1016/j.apenergy.2018.02.110.

[26] Committee on Climate Change, Reducing UK emissions. 2018 Progress Report to Parliament, (2018). www.theccc.org.uk/publications.

[27] L. Hirth, F. Ueckerdt, O. Edenhofer, Integration costs revisited - An economic framework for wind and solar variability, Renew. Energy. 74 (2015) 925-939. doi:10.1016/j.renene.2014.08.065.

[28] D. Newbery, M.G. Pollitt, R.A. Ritz, W. Strielkowski, Market design for a high-renewables European electricity system, Renew. Sustain. Energy Rev. 91 (2018) 695-707. https://doi.org/10.1016/j.rser.2018.04.025.

[29] M. Grubb, D. Newbery, UK Electricity Market Reform and the Energy Transition: Emerging Lessons, Cambridge, 2018. www.eprg.group.cam.ac.uk.

[30] BEIS, Electricity Generation Costs, Department for Business, Energy \& Industrial Strategy, 2016.

https://assets.publishing.service.gov.uk/government/uploads/system/uploads/attachment_data/f ile/566567/BEIS_Electricity_Generation_Cost_Report.pdf.

[31] D. Newbery, Tales of two islands - Lessons for EU energy policy from electricity market reforms in Britain and Ireland, Energy Policy. 105 (2017) 597-607. doi:10.1016/j.enpol.2016.10.015.

[32] M. Lockwood, The development of the Capacity Market for electricity in Great Britain. EPG Working Paper, 2017. http://projects.exeter.ac.uk/igov/working-paper-the-development-of-thecapacity-market-for-electricity-in-great-britain/.

[33] SKM, Growth Scenarios for UK Renewables Generation and Implications for Future Developments and Operation of Electricity Networks, BERR, London, 2008. https://assets.publishing.service.gov.uk/government/uploads/system/uploads/attachment_data/f ile/42969/1_20090501131535_e SKMRESBERRFinalReport.pdf. 
[34] R. Green, N. Vasilakos, The Long-term Impact of Wind Power on Electricity Prices and Generating Capacity. Centre for Competition Policy Working Paper, 2011.

https://www.birmingham.ac.uk/Documents/college-social-sciences/business/economics/2010papers/economics-papers-2011/economics-papers-2011/11-09.pdf.

[35] F. Ueckerdt, R. Brecha, G. Luderer, Analyzing major challenges of wind and solar variability in power systems, Renew. Energy. 81 (2015) 1-10. doi:10.1016/j.renene.2015.03.002.

[36] NASA, Earth Data, MERRA 2, (2019). https://disc.gsfc.nasa.gov/datasets?project=MERRA-2 (accessed August 30, 2019).

[37] D. Drew, H. Bloomfield, P. Coker, J. Barlow, D. Brayshaw, MERRA Derived Hourly Time Series of GB-Aggregated Wind Power, Solar Power and Demand, University of Reading. Dataset, (2019). doi:10.17864/1947.191.

[38] A. Boilley, L. Wald, Comparison between meteorological re-analyses from ERA-Interim and MERRA and measurements of daily solar irradiation at surface, Renew. Energy. (2015). doi:10.1016/j.renene.2014.09.042.

[39] D.R. Drew, P.J. Coker, H.C. Bloomfield, D.J. Brayshaw, J.F. Barlow, A. Richards, Sunny windy sundays, Renew. Energy. 138 (2019). doi:10.1016/j.renene.2019.02.029.

[40] National Grid, Future Energy Scenarios, (2018). http://fes.nationalgrid.com/fes-document/.

[41] A. Damm, J. Köberl, F. Prettenthaler, N. Rogler, C. Töglhofer, Impacts of $+2{ }^{\circ} \mathrm{C}$ global warming on electricity demand in Europe, Clim. Serv. (2017). doi:10.1016/j.cliser.2016.07.001.

[42] I. Tobin, S. Jerez, R. Vautard, F. Thais, E. Van Meijgaard, A. Prein, M. Déqué, S. Kotlarski, C.F. Maule, G. Nikulin, T. Noël, C. Teichmann, Climate change impacts on the power generation potential of a European mid-century wind farms scenario, Environ. Res. Lett. (2016). doi:10.1088/1748-9326/11/3/034013.

[43] I. Tobin, W. Greuell, S. Jerez, F. Ludwig, R. Vautard, M.T.H. Van Vliet, F.M. Breón, Vulnerabilities and resilience of European power generation to $1.5^{\circ} \mathrm{c}, 2^{\circ} \mathrm{C}$ and $3{ }^{\circ} \mathrm{C}$ warming, Environ. Res. Lett. (2018). doi:10.1088/1748-9326/aab211.

[44] P.L.M. Gonzalez, D.J. Brayshaw, G. Zappa, The contribution of North Atlantic atmospheric circulation shifts to future wind speed projections for wind power over Europe, Clim. Dyn. (2019). doi:10.1007/s00382-019-04776-3.

[45] J. Moemken, M. Reyers, H. Feldmann, J.G. Pinto, Future Changes of Wind Speed and Wind Energy Potentials in EURO-CORDEX Ensemble Simulations, J. Geophys. Res. Atmos. (2018). doi:10.1029/2018JD028473.

[46] S. Jerez, I. Tobin, M. Turco, P. Jiménez-Guerrero, R. Vautard, J.P. Montávez, Future changes, or lack thereof, in the temporal variability of the combined wind-plus-solar power production in Europe, Renew. Energy. (2019). doi:10.1016/j.renene.2019.02.060.

[47] J. Müller, D. Folini, M. Wild, S. Pfenninger, CMIP-5 models project photovoltaics are a noregrets investment in Europe irrespective of climate change, Energy. (2019). doi:10.1016/j.energy.2018.12.139.

[48] S. Kozarcanin, H. Liu, G.B. Andresen, 21st Century Climate Change Impacts on Key Properties of a Large-Scale Renewable-Based Electricity System, Joule. (2019). doi:10.1016/j.joule.2019.02.001.

[49] M.T. Craig, I. Losada Carreño, M. Rossol, B.M. Hodge, C. Brancucci, Effects on power system operations of potential changes in wind and solar generation potential under climate change, Environ. Res. Lett. (2019). doi:10.1088/1748-9326/aaf93b.

[50] L. Hirth, I. Ziegenhagen, Balancing power and variable renewables: Three links, Renew. Sustain. Energy Rev. 50 (2015) 1035-1051. doi:10.1016/j.rser.2015.04.180.

[51] D.S. Wilks, Statistical Methods in the Atmospheric Sciences, Third, Academic Press, London, 
2011.

716

[52] National Grid, Winter Outlook 2018/19, (2018).

https://www.nationalgrideso.com/document/127551/download.

718 